\title{
Rancang Bangun Aplikasi Sistem Informasi Kegiatan dan Transparansi Keuangan Rukun Warga 04 Graha Mitra Citra Panongan
}

\author{
Hengki Rusdianto $^{1 *}$, Rachmat Destriana ${ }^{2}$, Bayu Enggar Prastyawan ${ }^{3}$ \\ 1,2,3,4 Program Studi Teknik Informatika, Fakultas Teknik, Universitas Muhammadiyah Tangerang \\ Jl. Perintis Kemerdekaan 1/33 Cikokol Kota Tangerang \\ Co Responden Email: hengki.rusdianto@gmail.com
}

Article history

Received Nov 17, 2020

Revised Jan 15, 2021

Accepted Jan 30, 2021

Available online Feb 28, 202

Keywords

Information Systems,

Community Harmony (RW),

Financial Transparency,

Unified Modelling Language

(UML), PHP
Abstract

Rukun Warga $(R W)$ is a community institution formed through deliberation with the local community to provide services to residents. Rukun Warga $(R W)$ has an important role in maintaining and preserving the values of people's lives based on cooperation and kinship. In facilitating the implementation of government work in rural or urban development and communities, and the welfare of the community. Therefore, Rukun Tetangga (RT) and Rukun Warga (RW) must provide good services for citizens who create a conducive society. People need services and financial transparency at all times, but services can only be provided to residents during the day or on holidays only because the Rukun Warga (RW) Board has a personal interest. These problems can be solved by building a websitebased information system that is able to become a medium of communication between citizens and the Management of Rukun Warga $(R W)$. In this case the author uses unified modelling language (UML) used to analyze the design of the system to be created, for testing done using black box testing method, as well as MySql as database and programming language used is PHP.
Riwayat

Diterima 17 Nov 2020

Revisi 15 Jan 2021

Disetujui 30 Jan 2021

Terbit 28 Feb 2021

Kata Kunci

Kata kunci: Sistem Informasi,

Rukun Warga (RW),

Transparansi Keuangan,

Unified Modelling Language

(UML), PHP.
Abstrak

Rukun Warga (RW) adalah lembaga masyarakat yang dibentuk melalui musyawarah dengan masyarakat setempat untuk memberikan layanan kepada warga. Rukun Warga (RW) memiliki peran penting dalam menjaga dan melestarikan nilai-nilai kehidupan masyarakat berdasarkan kerjasama dan kekerabatan. Dalam memfasilitasi pelaksanaan pekerjaan pemerintahan dalam pembangunan dan masyarakat pedesaan atau perkotaan, dan kesejahteraan masyarakat. Oleh karena itu, Rukun Tetangga (RT) dan Rukun Warga (RW) harus memberikan layanan yang baik bagi warga yang menciptakan masyarakat yang kondusif. Masyarakat membutuhkan layanan serta transparansi keuangan setiap saat, tetapi layanan hanya dapat diberikan kepada warga di siang hari atau pada hari libur saja karena Pengurus Rukun Warga (RW) memiliki kepentingan pribadi. Masalah-masalah ini dapat diatasi dengan membangun sistem informasi berbasis website yang mampu menjadi media komunikasi antara Warga dan Pengurus Rukun Warga (RW). Dalam hal ini penulis menggunakan bahasa Unified Modelling Language (UML) digunakan untuk menganalisis desain sistem yang akan dibuat, untuk pengujian dilakukan dengan menggunakan metode pengujian Black Box, serta MySql sebagai database dan bahasa pemrograman yang digunakan adalah PHP. 


\section{Pendahuluan}

Dengan semakin pesatnya perkembangan teknologi informasi khususnya teknologi komputer sebagai mesin pengolahan dan penyimpanan data untuk menciptakan informasi yang cepat, tepat serta akurat dan bisa dimanfaatkan sesuai dengan kebutuhan. Kecepatan penyampaian sebuah informasi serta akses data merupakan salah satu faktor utama media pendukung sebuah organisasi baik itu pemerintahan, institusi, maupun perusahaan untuk dapat berkembang dengan baik.

Hal ini dikarenakan, suatu sistem informasi yang optimal akan mampu meningkatkan kinerja organisasi yang pada akhirnya dapat mewujudkan sebuah kemajuan lebih baik bagi organisasi tersebut. Salah satunya adalah sistem informasi kegiatan dan transparansi keuangan yang merupakan sebuah sistem informasi yang dirancang untuk proses kegiatan dan transparansi keuangan rukun warga yang meliputi data warga serta pencatatan. Dan dengan adanya sistem ini diharapkan mampu memberikan informasi mengenai jumlah warga serta akan terwujudnya database warga secara bertahap.

Pada saat ini sistem informasi kegiatan dan transparansi keuangan pada wilayah Rukun Warga 04 Graha Mitra Citra Panongan masih bersifat pembukuan, pengarsipan, serta dokumen sehingga rawan terjadinya kerusakan dokumen atau hilangnya data warga yang dapat mengakibatkan ketidak akuratan jumlah data warga terlebih dengan warga baru yang dating. Dengan digunakan satu jenis surat pengantar untuk berbagai keperluan seperti pindah, lahir ataupun surat keterangan lainnya tentu bisa menimbulkan kesalahpahaman ditingkat organisasi.

Menurut Abdul Hafiz Tanjung (2011) transparansi adalah keterbukaan dan kejujuran kepada masyarakat berdasarkan pertimbangan bahwa masyarakat memiliki hak untuk mengetahui secara terbuka dan menyeluruh atas pertanggung jawaban pemerintah dalam sumber daya yang dipercayakan kepadanya dan ketaatannya pada peraturan perundangundangan. Menurut Hutahaean (2014:13), sistem informasi adalah suatu sistem di dalam suatu organisasi yang mempertemukan kebutuhan pengelolaan transaksi harian, mendukung operasi, bersifat manajerial, dan kegiatan strategi dari suatu organisasi dan menyediakan pihak luar tertentu dengan laporan-laporan yang dibutuhkan.

\section{Metode Penelitian}

2.1 Jenis Penelitian
Jenis penelitian yang digunakan dalam proses pembuatan skripsi ini adalah jenis penelitian deskriptif, karena penelitian deskriptif merupakan penelitian yang berusaha mendeskripsikan dan menginterprestasikan sesuatu, misalnya kondisi atau hubungan yang ada, pendapatan yang berkembang, proses yang sedang berlangsung. Dalam penelitian ini, tentang kegiatan dan transparansi keuangan.

2.2 Metode Pengumpulan Data

Dalam menyelesaikan skripsi ini, baik dalam pengumpulan data maupun informasi yang diperlukan untuk mendapatkan kebenaran materi uraian pembahasan, penulis memperoleh data yang diinginkan melalui pengumpulan data dengan metode pengumpulan data yang terdiri dari :

1. Metode Wawancara.

Peneliti telah menyiapkan daftar pertanyaan yang berkaitan dengan pengumpulan informasi, untuk ditanyakan kepada: Ketua RW, Sekretaris dan Bendahara.

2. Metode Observasi.

Tujuan dilakukannya observasi adalah guna mengetahui bagaimana jalannya sistem manual atau saat ini dan mengetahui masalah-masalah apa saja dengan masih digunakannya sistem manual.

3. Metode Studi Pustaka.

Dalam melakukan studi pustaka penulis melengkapi kekurangan-kekurangan data yang diperoleh dari lapangan. Pengumpulan data dengan cara mengambil dari sumber-sumber media cetak maupun elektronik yang dapat dijadikan acuan pembahasan masalah.

2.3 Teknik Analisis Sistem

Teknik analisis yang digunakan dalam penelitian ini menggunakan pendekatan Object Oriented Analysis (OOA) atau analisis berorientasi obyek pada UML. Proses analysis dilakukan terhadap hasil tahapan pengumpulan data dengan wawancara, observasi, dan studi pustaka untuk mendapatkan spesifikasi kebutuhan sistem yang dikembangkan.

\subsection{Metode Pengembangan Sistem}

Metode prototype dimulai dari mengumpulkan kebutuhan user terhadap perangkat lunak yang akan dibuat. Lalu dibuat program prototype agar user lebih terbayang dengan apa yang sebenarnya diinginkan. Program ini biasanya menyediakan tampilan dengan simulasi alur perangkat lunak sebagai tampak seperti perangkat lunak yang sudah jadi. Program prototype ini dievaluasi oleh user sampai ditemukan spesifikasi yang sesuai 
dengan keinginan user. Berikut adalah gambar dari model prototype (Pressman 2005) :

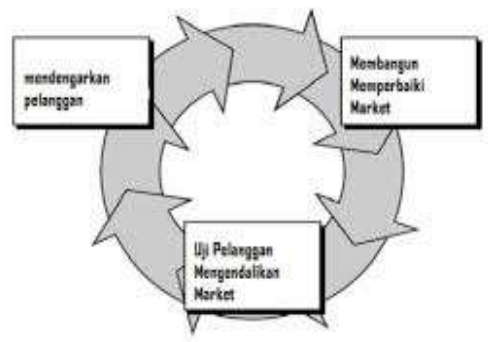

Gambar 3.1 Model Pengembangan Sistem Prototype menurut Pessman (2005)

Langkah-langkah penelitian akan melalui beberapa tahapan proses pengerjaan yaitu :

1. Mendengan user

$$
\text { Pada tahap ini }
$$

dilakukan pengumpulan kebutuhan dari sistem dengan cara mendengarkan keluhan dari user. Untuk membuat suatu sistem yang sesuai kebutuhan, maka harus diketahui terlebih dahulu bagaimana sistem yang sedang berjalan untuk kemudian mengetahui masalah yang terjadi.

2. Merancang dan membuat prototype

Pada tahap ini, dilakukan perancangan dan pembuatan prototype sistem. Prototype yang dibuat disesuaikan dengan kebutuhan sistem yang telah didefinisikan sebelumnya dari keluhan user atau pengguna.

$$
\text { 3. Uji Coba }
$$

Pada tahap ini, prototype dari sistem di uji coba oleh user atau pengguna. Kemudian dilakukan evaluasi kekurangan-kekurangan dari kebutuhan user. Pengembang kemudian kembali mendengarkan keluhan dari user atau pengguna untuk memperbaiki prototype yang ada.

(Coding)

$$
\text { 3.5 Tahap Pengkodean Sistem }
$$

Pada tahap ini prototype yang sudah disetujui oleh user diterjemahkan ke dalam Bahasa pemrograman yang sesuai. Tahap ini adalah generasi kode program (coding) dimana desain yang telah dibuat harus diterjemahkan ke dalam bentuk mesin yang sesuai. Jika desain yang dilakukan dengan cara yang lengkap, maka pembuatan kode program (coding) dapat diselesaikan dengan secara mekanisme yang ada.

\section{Hasil dan Pembahasan}

\section{PENELITIAN \\ 4. PEMBAHASAN HASIL}

4.1 Use Case Sistem Berjalan

Diagram use case dari sistem yang berjalan saat ini seperti terlihat dalam gambar 4.1 berikut ini.

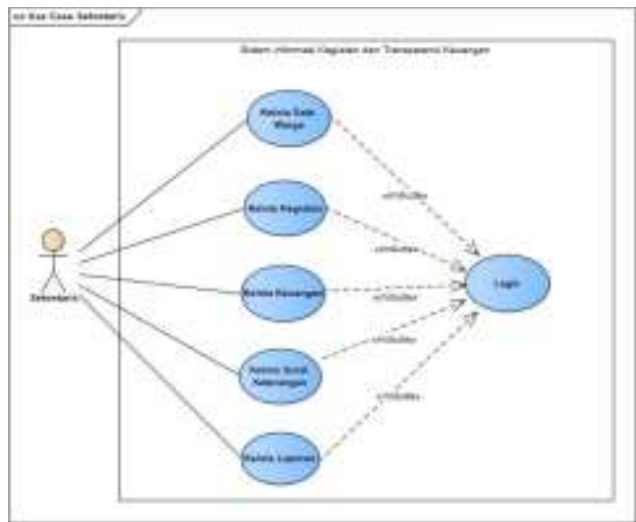

Gambar 4.1 Diagram use case sistem berjalan

\subsection{Diagram Use Case}

Diagram use case menggambarkan alur kerja sistem dengan cara yang sangat sederhana, fungsi utama dari sistem dan berbagai jenis pengguna yang akan berinteraksi dengan sistem, sebagaimana gambar 4.2 berikut ini:

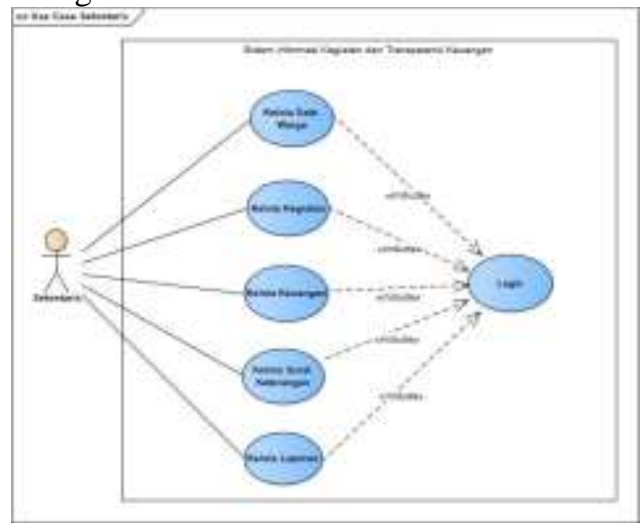

Gambar 4.2 Diagram use case sekretaris sistem usulan

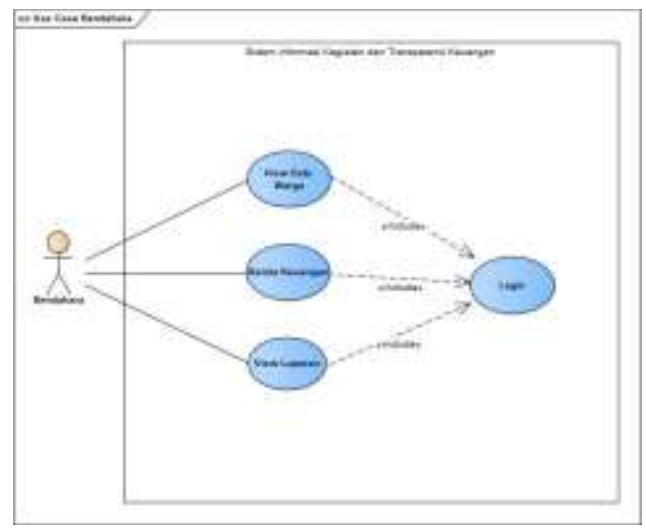


Gambar 4.3 Diagram use case bendahara sistem usulan

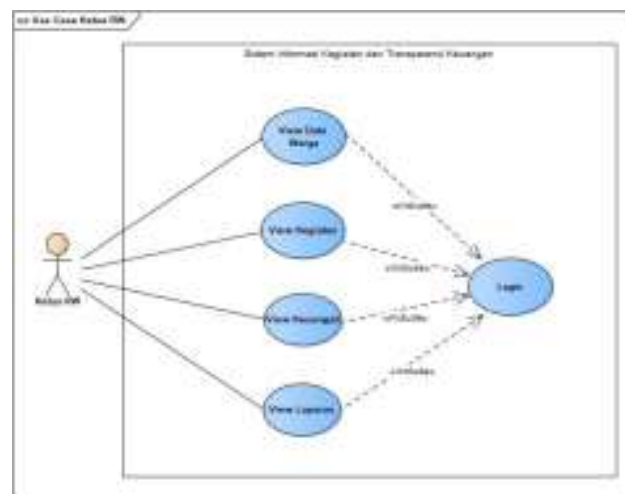

Gambar 4.4 Diagram use case ketua rw sistem usulan

4.3 Diagram Sequence

Diagram sequence merupakan diagram urutan yang menggambarkan objek yang berpartisipasi dalam use case dan message atau keterangan aktifitas yang dilakukan antaranya dari waktu ke waktu untuk sebuah use case. Gambar 4.3 menggambarkan diagram sequence dari kelola data warga yang dilakukan oleh actor Sekretaris.

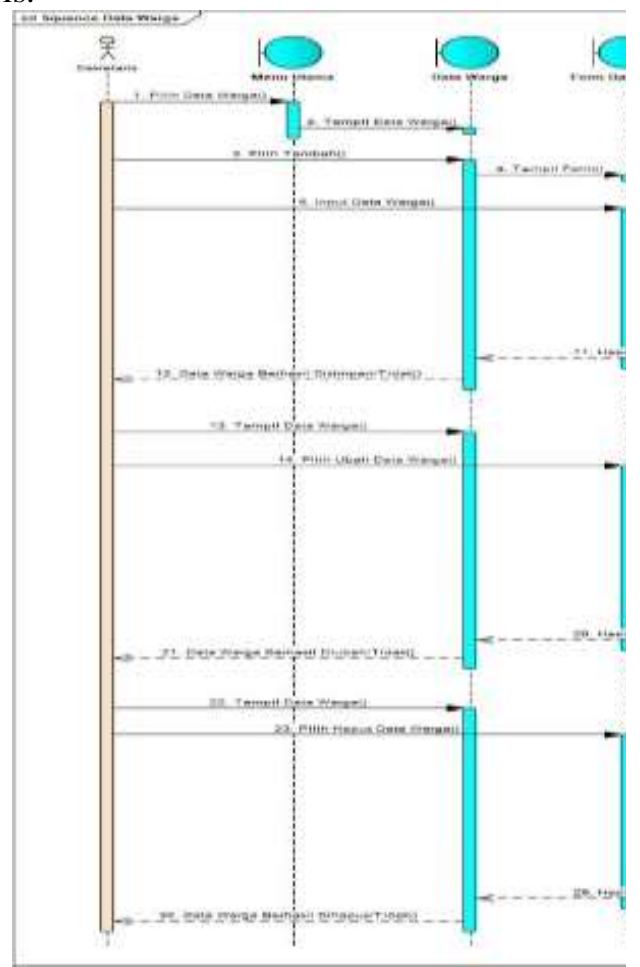

Gambar 4.5 Diagram Sequence kelola data warga

4.4 Rancangan SIKRW

4.4.1 Tampilan Menu Log in

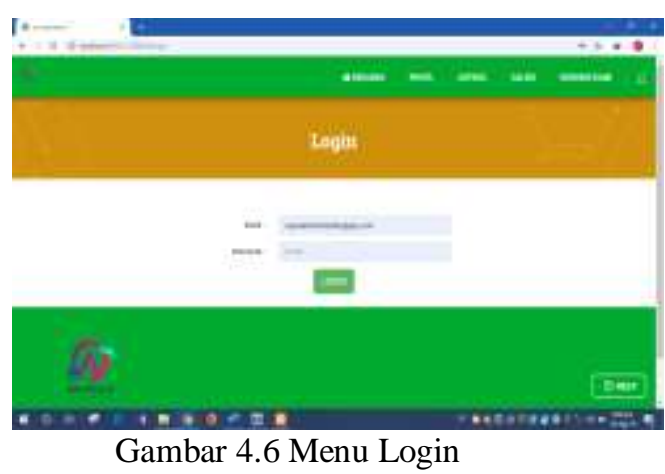

4.4.2 Tampilan Menu Utama

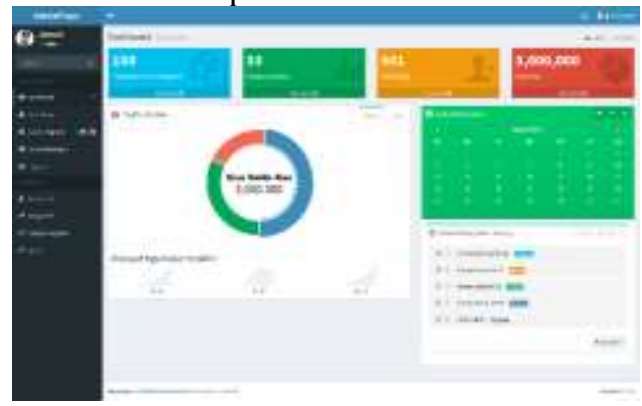

Gambar 4.7 Menu Utama

4.4.3 Tampilan Menu Data Warga

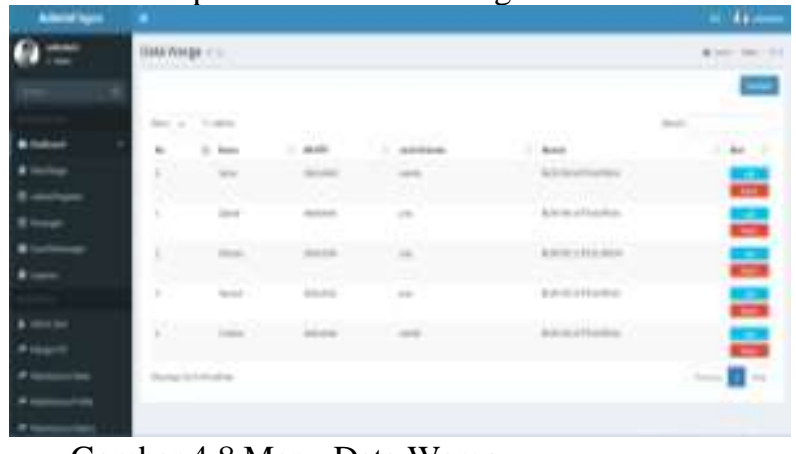

Gambar 4.8 Menu Data Warga

\subsubsection{Tampilan Menu Kelola Kegiatan}

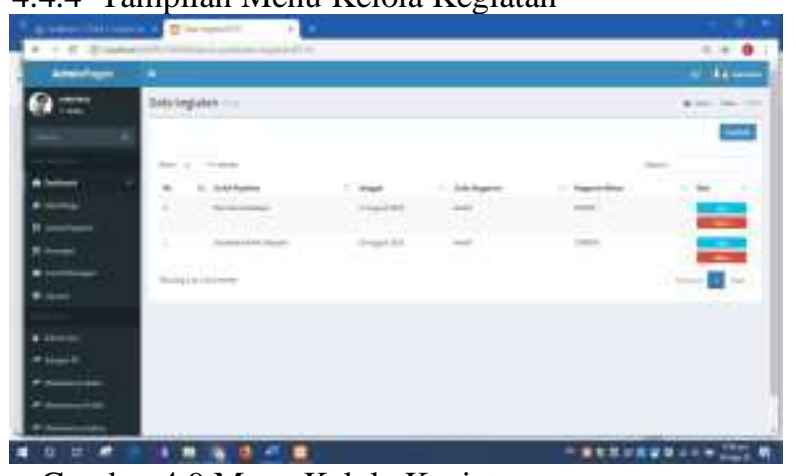

Gambar 4.9 Menu Kelola Kegiatan

\subsubsection{Tampilan Menu Kelola Keuangan}




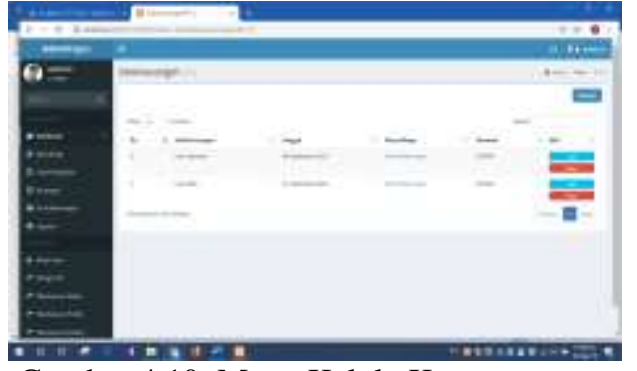

Gambar 4.10. Menu Kelola Keuangan

4.4.6 Tampilan Menu Surat Keterangan

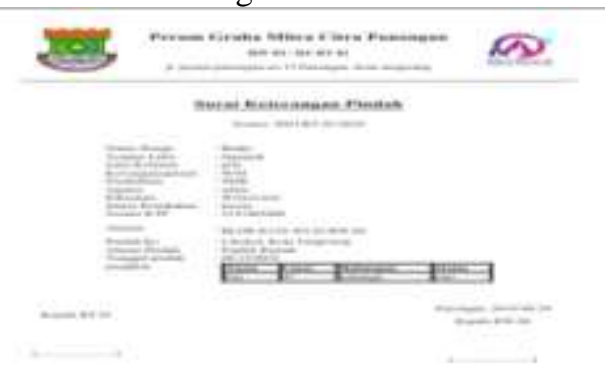

Gambar 4.11 Menu Surat Keterangan

4.4.7 Tampilan Menu Laporan

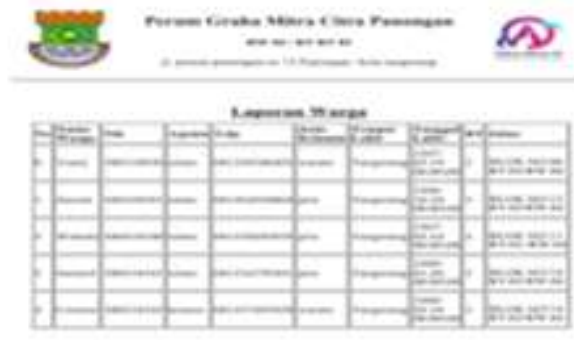

Gambar 4.12 Menu Laporan

\section{Kesimpulan}

Berdasarkan hasil penelitian dari Rancang Bangun Aplikasi Sistem Informasi Kegiatan dan Transparansi Keuangan Rukun Warga 04 Graha Mitra Citra Panongan, maka dapat diambil beberapa kesimpulan bahwa Sistem informasi ini, hanya bisa digunakan oleh pengurus rukun warga, Sistem informasi ini, hanya untuk bagian kegiatan dan transparansi keuangan rukun warga, Dengan pengolahan data yang dilakukan secara komputerisasi dapat mempermudah proses pencarian data warga menjadi lebih cepat dan efektif, Dengan adanya sistem informasi ini penginputan dan pengupdate-an serta pencarian data warga yang melakukan pembuatan surat keterangan kelahiran, kematian dan pindah dapat meminimalisasikan kesalahan pada proses penambahan data serta mempermudah proses pencarian data warga, dengan adanya sistem informasi ini dapat mempersingkat dan mempermudah dalam pembuatan laporan warga setiap bulannya, dengan adanya penyimpanan data yang sudah berbentuk database, maka kemungkinan tidak akan menjadi duplikasi data.

\section{Daftar Referensi}

Abdul Hafiz Tanjung. (2011). Akuntansi, Transparansi, dan Akuntabilitas Keuangan Publik (Sebuah Tantangan).

Alim. (2013). Step by Step Desain Proyek Menggunakan UML. Yogyakarta: Andi Offset.

James, A. O’Brien \& George, M. M. (2014). Sistem Informasi Manajemen. Jakarta: Salemba Empat.

Hutahaean, Jeperson. (2014). Konsep Sistem Imformasi. Yogyakarta: Deepublish.

Murad, Dina Fitria, Kusniawati. Nia, Asyanto. Agus. (2013). Aplikasi Intelligence Website Untuk Penunjang Laporan PAUD Pada Himpaudi Kota Tangerang. Jurnal CCIT. Tangerang: Perguruan Tinggi Raharja. Vol. 7, No. 1, September 2013.

Kustiyahningsih, Yeni dan Amanisa, Rosa devie. (2010). Pemrograman Basis Data Berbasis Web Menggunakan PHP \& MySQL.Graha IImu. Yogyakarta.

Rosa, A. S. dan Shalahuddin, M. (2014). Rekayasa Perangkat Lunak Terstruktur Dan Berorientasi Obyek. Bandung: Informatika. 